\title{
Extragastric MALT lymphoma
}

\section{A C Wotherspoon}

\section{A case of mucosa associated lymphoid tissue (MALT) lymphoma of the oesophagus, diagnosed and treated by endoscopic mucosal resection}

A pproximately $40 \%$ of all nonHodgkin's lymphomas occur in extranodal locations. The majority are of the diffuse large B cell type but extranodal marginal zone $\mathrm{B}$ cell lymphoma of mucosa associated lymphoid tissue (MALT lymphoma) is the commonest extranodal small B cell non-Hodgkin's lymphoma. Approximately $37 \%$ of extranodal lymphomas occur in the gastrointestinal tract and oesophagus. ${ }^{1}$ The commonest site is the stomach $(23 \%$ of extranodal lymphomas) followed by the small intestine $(7.5 \%)$ and the colorectum (5.5\%). Primary lymphoma of the oesophagus is very rare accounting for only three cases in a series of 1467 reported by Freeman and colleagues. ${ }^{1}$ The majority of lymphomas that have been reported in the literature date from before the advent of current knowledge about MALT lymphoma, its pathogenesis, molecular genetics, and treatment but in this issue of Gut, Hosaka and colleagues ${ }^{2}$ describe in detail a case of primary oesophageal lymphoma, diagnosed and treated by endoscopic mucosal resection [see page 281]. Their case illustrates several interesting issues in the biology and treatment of MALT lymphomas.

The initiating step in the pathogenesis of MALT lymphoma at all sites is the acquisition of organised lymphoid tissue. This will have the characteristic features of MALT with a germinal centre, mantle and marginal zone, plasma cell differentiation, and an associated T cell component. B cells may infiltrate epithelial structures, if present, to mimic a lymphoepithelium similar to that seen in native MALT in Peyer's patches. In the majority of cases in the stomach (but not all) the stimulus for acquisition of MALT is Helicobacter pylori infection. ${ }^{3}$ In the small intestine an infective organism is also implicated, as immunoproliferative small intestinal disease will also respond to antibiotic therapy in the early stages. In the skin, some cases of MALT lymphoma have been associated with Borrelia infection. ${ }^{5}$ In other sites no infective organisms have been implicated and in some organs the initiating step appears to be clearly related to autoimmune disease (for example, thyroid, salivary gland). Outside the stomach, $H$ pylori is unlikely to be involved in the pathogenesis of these lymphomas. Although there are occasional reports of extragastric MALT lymphomas responding to anti-H pylori-type antibiotic combinations, ${ }^{6-8}$ this is likely to indicate a role for another bacterial organism as $H$ pylori does not normally colonise these extragastric sites and has been completely absent in some patients in whom the lymphoma responded to this therapy. ${ }^{7}$

Acquired MALT appears to be in some way unstable. In particular, the cells in the marginal zone appear to be susceptible to neoplastic transformation within this environment leading to a higher than expected incidence of marginal zone lymphoma in these sites compared with lymphomas derived from other $B$ cell compartments. This is in contrast with the finding in native MALT, such as in the terminal ileum, where marginal zone (MALT) lymphoma is rare but lymphomas from the other compartments are more frequent (follicular lymphoma, mantle cell lymphoma). The explanation for this difference remains conjectural but one factor may be the absence of $M$ cells in areas of acquired MALT which potentially results in disorganised antigen processing within the local environment.

The absence of API2-MALTl chimeric transcript in the case described by Hosaka et al is also of interest. The $\mathrm{t}(11 ; 18)$ has been found most frequently in MALT lymphomas arising in the stomach and lung (up to $40 \%$ of cases) but appears less common in those MALT lymphomas in other sites." In the stomach, the presence of this translocation may indicate failure to respond to $H$ pylori eradication, more aggressive local invasiveness, and lack of potential for high grade transformation.'

The use of mucosal resection for MALT lymphoma is also of interest. This has been reported as a therapeutic option in some cases of gastric MALT lymphoma. In general, MALT lymphomas respond well to local resection. Indeed, local resection was the mainstay for gastric MALT lymphoma management in many centres before the role of
Helicobacter had been elucidated and may still be used for MALT lymphomas at other sites such as the salivary gland, thyroid, and skin. Hence mucosal resection for superficial lesions would appear to be an attractive option as it is associated with very low morbidity. The apparently excellent results achieved with locally directed therapy should however be carefully monitored and these patients require extended follow up due to the potential for local relapse. This is due to the presence of microscopic foci of lymphoma which may potentially be present throughout the organ. In the stomach, multifocal microscopic deposits of lymphoma throughout the gastric mucosa is well documented. ${ }^{10}{ }^{11}$ The natural history of skin MALT lymphoma, with relapses occurring in other cutaneous sites over the course of a number of years, suggests that a similar distribution of microscopic disease may be present throughout the integument. The presence of two lesions in the case described by Hosaka et al may also reflect this distribution within the oesophagus. Therefore, a policy of close follow up of the entire organ should be adopted when local therapy has been used to treat MALT lymphoma. For this purpose, paired organs (for example, salivary glands, conjunctiva, lung) should be considered as a single system as the theory of lymphoma cell circulation and homing would predict that bilateral multifocal involvement should be expected.

Gut 2002;51:148-150

\section{Author's affiliation}

A C Wotherspoon, Department of Histopathology, Royal Marsden Hospital, Fulham Road, London SW3 6JJ, UK; Andrew.Wotherspoon@rmh.nthames.nhs.uk

\section{REFERENCES}

1 Freeman C, Berg JW, Cutler SJ. Occurrence and prognosis of extranodal lymphoma. Cancer 1972;29:252-60.

2 Hosaka S, Nakamura N, Akamatsu T, et al. A case of primary low grade mucosa associated lymphoid tissue (MALT) lymphoma of the oesophagus. Gut 2002 51:281-4.

3 Wotherspoon AC, Ortiz-Hidalgo C, Falzon $M R$, et al. Helicobacter pylori-associated gastritis and primary B-cell gastric lymphoma. Lancet 1991;338:1175-6.

4 Ben-Ayed F, Halphen M, Naijar T, et al. Treatment of alpha chain disease-results of a prospective study of 21 Tunisian patients by the Tunisian-French intestinal lymphoma study group. Cancer 1989;63:1251-6.

5 Roggero E, Zucca E, Mainetti C, et al. Eradication of Borrelia burgdorferi infection in primary marginal zone B-cell lymphoma of skin. Hum Pathol 2000;31:263-8. 
6 Alkan S, Karcher DS, Newman MA, et al. Regression of salivary gland MALT lymphoma after treatment for Helicobacter pylori. Lancet 1996;348:268-9.

7 Inove F, Chiba T. Regression of MALT lymphoma of the rectum after anti-H.pylori therapy in a patient negative for H.pylori. Gastroenterology 1999;117:514-15.
8 Raderer M, Pfeffel F, Pohl G, et al. Regression of colonic low grade B cell lymphoma of mucosa associated lymphoid tissue type after eradication of Helicobacter pylori. Gut 2001;46:133-5

9 Wotherspoon AC, Dogan A, Du MQ. Mucosa-associated lymphoid tissue lymphoma. Curr Opin Hematol 2002;9:50-5.
10 Wotherspoon AC, Doglioni C, Isaacson PG. Low-grade gastric B-cell lymphoma of mucosa-associated lymphoid tissue (MALT): a multifocal disease. Histopathology 1992;20:29-34

11 Du MQ, Diss TC, Dogan A, et al. Clone-specific PCR reveals wide dissemination of gastric MALT lymphoma to the gastric mucosa. J Pathol 2000;1 92:488-93.

\section{New GUT online submission and review system}

The Editors of GUT are pleased to inform authors and reviewers of its new online submission and review system. Bench>Press is a fully integrated electronic system which uses the internet to allow rapid and efficient submission of manuscripts, plus the entire peer review process to be conducted online.

Authors can submit their manuscript in any standard word processing software. Graphic formats acceptable are: .jpg, .tiff, .gif, and eps. Text and graphic files are automatically converted to PDF for ease of distribution and reviewing purposes. Authors are asked to approve their submission before it formally enters the reviewing process.

To access the system click on "SUBMIT YOUR MANUSCRIPT HERE" on the GUT homepage: http://www.gutjnl.com/, or you can access Bench>Press directly at http:// submit-gut.bmijournals.com/.

We are very excited with this new development and we would encourage authors and reviewers to use the on-line system where possible. It really is simple to use and should be a big improvement on the current peer review process. Full instructions can be found on Bench>Press http://submit-gut.bmijournals.com/, and GUT online at http://www. gutjnl.com/. Please contact Natalie Davies, Project Manager, ndavies@bmigroup.com for further information.

\section{PRE-REGISTER WITH THE SYSTEM}

We would be grateful if all GUT authors and reviewers pre-registered with the system. This will give you the opportunity to update your contact and expertise data, allowing us to provide you with a more efficient service.

\section{Instructions for registering}

1. Enter http://submit-gut.bmijournals.com

2. Click on "Create a New Account" in the upper left hand side of the Bench>Press homepage

3. Enter your email address in the space provided.

4. Please be sure to enter the email address that you received this email message at.

You will be given the opportunity to change this once you have created an account.

5. Choose a password for yourself and enter it in the spaces provided.

6. Complete the question of your choice to be used in the event you cannot remember your password at a later time.

7. Click on the "Save" button at the bottom of the screen.

8. Check the e-mail account you registered under. An email will be sent to you with a verification number and URL.

9. Once you receive this verification number, click on the URL hyperlink and enter the verification number in the relevant field. This is for security reasons and to check that your account is not being used fraudulently.

10. Enter/amend your contact information, and update your expertise data. 